\title{
Sulforaphane protects against acrolein-induced oxidative stress and inflammatory responses: modulation of Nrf-2 and COX-2 expression
}

\author{
Wang-Sen Qin, Yu-Hui Deng, Fa-Cai Cui
}

Department of Clinical Laboratory, Henan Provincial People’s Hospital, Henan, China

Submitted: 18 July 2014

Accepted: 7 August 2014

Arch Med Sci 2016; 12, 4: 871-880

DOI: 10.5114 /aoms.2016.59919

Copyright $@ 2016$ Termedia \& Banach

\section{Abstract}

Introduction: Acrolein (2-propenal) is a reactive $\alpha, \beta$-unsaturated aldehyde which causes a health hazard to humans. The present study focused on determining the protection offered by sulforaphane against acrolein-induced damage in peripheral blood mononuclear cells (PBMC).

Material and methods: Acrolein-induced oxidative stress was determined through evaluating the levels of reactive oxygen species, protein carbonyl and sulfhydryl content, thiobarbituric acid reactive species, total oxidant status and antioxidant status (total antioxidant capacity, glutathione, superoxide dismutase, catalase, glutathione peroxidase, glutathione-S-transferase activity). Also, Nrf-2 expression levels were determined using western blot analysis. Acrolein-induced inflammation was determined through analyzing expression of cyclooxygenase-2 by western blot and PGE2 levels by ELISA. The protection offered by sulforaphane against acrolein-induced oxidative stress and inflammation was studied.

Results: Acrolein showed a significant $(p<0.001)$ increase in the levels of oxidative stress parameters and down-regulated Nrf-2 expression. Acrolein-induced inflammation was observed through upregulation $(p<0.001)$ of COX-2 and PGE2 levels. Pretreatment with sulforaphane enhanced the antioxidant status through upregulating Nrf-2 expression $(p<0.001)$ in PBMC. Acrolein-induced inflammation was significantly inhibited through suppression of COX-2 $(p<0.001)$ and PGE2 levels $(p<0.001)$.

Conclusions: The present study provides clear evidence that pre-treatment with sulforaphane completely restored the antioxidant status and prevented inflammatory responses mediated by acrolein. Thus the protection offered by sulforaphane against acrolein-induced damage in PBMC is attributed to its anti-oxidant and anti-inflammatory potential.

Key words: oxidative stress, acrolein, sulforaphane, inflammation.

\section{Introduction}

Acrolein (2-propen-1-al) is a highly reactive ubiquitous environmental pollutant. Its exposure to humans occurs through multiple entries, including food, petroleum fuels, biodiesel and smoking tobacco products $[1,2]$. The maximum human exposure results from smoking tobacco products. Acrolein is formed as a byproduct during heating and combustion of food and petroleum products respectively. Chemical reactions involved in acrolein production include heat-induced dehydration of glycerol, retro-aldol cleavage of dehydrated carbohydrates, lipid peroxidation

\author{
Corresponding author: \\ Prof. Wang-Sen Qin \\ Department \\ of Clinical Laboratory \\ Henan Provincial \\ People's Hospital \\ 450000 Henan, China \\ Phone: +86-371-86113085 \\ E-mail: qinwangsen@ \\ gmail.com
}


of polyunsaturated fatty acids, and Strecker degradation of methionine and threonine. A recent study has identified that this highly reactive electrophilic compound as a major indoor pollutant in the United States [3], thus revealing its significant exposure from various sources.

Acrolein exposure results in various health hazards which are primarily mediated through oxidative stress and inflammation. However, the end result leads to cellular damage which occurs through apoptosis/necrosis. Acrolein-induced cellular damage mediates disease conditions such as chronic obstructive pulmonary disease, atherosclerosis, and Alzheimer's disease [4-6]. Acrolein-induced cellular damage has been shown to be mediated through apoptosis in various cells, including neutrophils [7], neurons [6], Chinese hamster ovary cells [8], and hepatocytes [9]. Cellular depletion of glutathione is one of the well-established mechanisms by which acrolein induces toxic effects $[10,11]$. It is known that acrolein is metabolized through sulfhydryl groups of glutathione forming 3-hydroxypropyl mercapturic acid which is excreted through urine [1]. In addition, circulating levels of acrolein in the bloodstream cause oxidative damage to the endothelial cells which ends in damage to the vascular wall. There are not many reports on acrolein-induced effects on peripheral blood mononuclear cells (PBMC). The main objective of the present study was to investigate the oxidative stress and cell death induced by acrolein on PBMC.

Since oxidative stress is mainly mediated through a reduction in the cellular antioxidant pool, the possible protective effect against acrolein-induced toxicity can be mediated by therapeutic intervention with antioxidants. Sulforaphane is an excellent antioxidant which is abundantly present in cruciferous vegetables [12]. Abundant data suggest the multiple potential of sulforaphane in different disease conditions including inhibition of phase II drug metabolizing enzyme, suppression of cell cycle progression and angiogenesis, apoptosis induction and anti-inflammatory properties. It has been well studied for its chemopreventive and protective properties, which are mainly attributed to its nuclear factor erythroid 2-related factor 2 (Nrf-2) induction. Nrf-2 is a redox sensitive transcription factor activated by antioxidants and upregulation of various phase II antioxidant enzymes. Recently Nrf-2 has gained importance as a therapeutic target in cytoprotection against oxidative stress. Sulforaphane is involved in regulating the glutathione levels through upregulating $\gamma$-GCS expression [13]. The protective effects of sulforaphane against various disease conditions such as cancer, neurodegenerative disorder, cardiovascular disease and diabetes have been re- ported previously [14-20]. Since oxidative stress and the downstream effects play a major role in acrolein-induced toxicity, the present study was aimed at investigating the protective effect of sulforaphane on acrolein-induced oxidative stress in human PBMC.

\section{Material and methods}

\section{PBMC isolation and treatment}

Peripheral blood mononuclear cells were isolated from whole blood from healthy volunteers using Ficoll-Paque PLUS (GE Healthcare Life Sciences). The study was conducted with the approval of the Henan Provincial People's Hospital Institutional Review Board for research on human subjects. Informed consent was acquired from all donors, and this study was carried out in compliance with the Declaration of Helsinki for ethical principles of conducting medical research. The blood was collected in EDTA tubes. The blood was diluted in PBS at a $1: 1$ ratio. An equal volume of diluted blood and Ficoll-Hypaque solution was added and centrifuged at $1500 \mathrm{rpm}$ (30 min; RT). After centrifugation, the PBMC layers (found at the interface between the plasma and the Ficoll-Paque Plus solution) were collected and washed twice in RPMI medium. The cells were washed three times with PBS (centrifuged at $1500 \mathrm{rpm}$ for $10 \mathrm{~min}$ each). The supernatant was discarded and the pellet was resuspended in PBS and the cell count was carried out by the trypan blue exclusion method in a hemocytometer. The cell viability was observed to be $>95 \%$.

Cell viability - MTT (3-(4,5-dimethylthiazol2-yl)-2,5-diphenyltetrazolium bromide) assay

The cells were seeded at a density of $1 \times 10^{5}$ cells/well in RPMI-1640 medium containing 10\% fetal bovine serum (FBS), $100 \mathrm{U} / \mathrm{ml}$ penicillin, and $100 \mathrm{U} / \mathrm{ml}$ streptomycin. The cells were treated with different concentrations of acrolein (10-60 $\mu \mathrm{M})$ to determine the cytotoxic effects. The cells were allowed to stand for $24 \mathrm{~h}$ after acrolein treatment. After the complete treatment schedule the cells were treated with MTT $(4 \mathrm{mg} / \mathrm{ml})$ for $3 \mathrm{~h}$. The formazan crystals were dissolved using DMSO and the absorbance was measured at $540 \mathrm{~nm}$ in a spectrophotometer [21]. The $I_{20}$ value $(30 \mu \mathrm{M})$ was calculated and used for the further studies.

The further cytoprotective effect of sulforaphane against acrolein-induced toxicity was determined. Cells were pretreated with sulforaphane at a concentration 1,5 and $10 \mu \mathrm{M}$ for $24 \mathrm{~h}$ followed by acrolein treatment for $24 \mathrm{~h}$. Cells pretreated with 5 and $10 \mu \mathrm{M}$ showed a better protective effect. So, further studies were carried 
out with a low concentration of sulforaphane, i.e. $5 \mu \mathrm{M}$. Treatment groups for the further studies were: group I - control; group II - sulforaphane (5 $\mu \mathrm{M})$; group III - acrolein $(30 \mu \mathrm{M})$; group IV - sulforaphane $(5 \mu \mathrm{M})+$ acrolein $(30 \mu \mathrm{M})$.

\section{Lactate dehydrogenase (LDH) assay}

Lactate dehydrogenase activity was determined using the LDH cytotoxicity kit (Bayer Diagnostics, France). The assay was performed according to the manufacturer's instructions. The absorbance was measured spectrophotometrically at $520 \mathrm{~nm}$. The results are expressed as \% LDH levels compared to the control.

\section{Reactive species generation (ROS)}

The cells at a density of $2 \times 10^{5}$ cells were used. The cells were incubated with $2^{\prime}, 7^{\prime}$-dichlorodihydrofluorescein diacetate (DCF-DA) for $30 \mathrm{~min}$. Cells were treated with acrolein in the presence/ absence of sulforaphane. For protective studies cells were treated with sulforaphane for $24 \mathrm{~h}$. Then sulforaphane was removed and treated with acrolein for $24 \mathrm{~h}$. At the end of the treatment schedule, all the treatment groups were centrifuged (1500 rpm, $10 \mathrm{~min}$ ) and re-suspended in PBS. The fluorescence intensity was measured at (excitation wavelength $480 \mathrm{~nm}$, emission wavelength $520 \mathrm{~nm}$ ). The results were formulated as $\%$ DCF fluorescence by comparing the values to those of control cells [22].

\section{Lipid peroxidation}

After the treatment schedule the cells from all the groups were sonicated and used for the lipid peroxidation assay. To the cell extract $8 \%$ SDS and $0.8 \%$ TBA in $20 \%$ acetic acid was added. The final volume of the assay was made up with water to $4 \mathrm{ml}$. The extract was boiled for $60 \mathrm{~min}$ at $90^{\circ} \mathrm{C}$. After cooling to room temperature, $2 \mathrm{ml}$ of butanol/ pyridine mixture was added and shaken vigorously. It was centrifuged at $4000 \mathrm{rpm}$ for $10 \mathrm{~min}$ and the organic layer was read at $532 \mathrm{~nm}$. The lipid peroxide content was expressed as nanomoles of TBA reactants/mg of protein [23]. Protein concentration was determined as previously described [24].

\section{Protein carbonyl and sulfhydryl content}

\section{Protein carbonyls}

The protein carbonyls formed were measured as described by Dalle-Donne et al. [25]. Briefly, the reaction between carbonyl groups in the sample and 2,4-dinitrophenylhydrazine (DNPH) results in the formation of 2,4-dinitrophenylhydrazone, which is quantified spectrophotometrically at $365 \mathrm{~nm}$. Carbonyl content was calculated using the extinction coefficient of $22 \times 10^{3} \mathrm{M}^{-1} \mathrm{C}^{-1}$. The results are expressed as nmoles of protein carbonyls/mg of protein.

\section{Protein sulphydryls}

The protein sulphydryls were determined using Ellman's reagent (5,5-dithiobis-2-nitrobenzoic acid), and absorbance was measured at $412 \mathrm{~nm}$ [26]. Sulfhydryl content was calculated using $13,600 \times 10^{3} \mathrm{M}^{-1} \mathrm{C}^{-1}$. The results are expressed as nmoles protein sulphydryls/mg protein. Protein concentration was determined as previously described [24].

\section{Total antioxidant capacity (TAC) and total oxidant status (TOS)}

Total antioxidant capacity was determined as described by Erel [27]. The principle involves determination of hydroxyl radical formation between the reactions of antioxidants in the sample against free radicals. The results are expressed as millimoles of Trolox equiv/l. TOS of serum was determined as described by Erel [28]. The basic principle involves oxidation of ferrous ion-o-dianisidine complex to ferric ion by the oxidants. The colored complex formed in the presence of xylenol orange is measured spectrophotometrically. The absorbance is directly proportional to the amount of oxidant molecules. The results are expressed as $\mu \mathrm{mol} \mathrm{H}_{2} \mathrm{O}_{2}$ equiv./l.

\section{Antioxidant enzymes}

\section{Glutathione (GSH) content}

The principle involves reaction between 5,5 dithiobis (2-nitrobenzoic acid) (DTNB) and reduced GSH to form a yellow compound which is measured at $405 \mathrm{~nm}$ spectrophotometrically (Moron et al., 1979) [29].

\section{Superoxide dismutase (SOD) activity}

The assay is based on reduction of nitroblue tetrazolium (NBT). Auto-oxidation of pyrogallol was measured by the increase in absorbance $(420 \mathrm{~nm})$ at 30-second intervals for $3 \mathrm{~min}$. $1 \mathrm{U}$ of SOD activity = amount required for $50 \%$ inhibition of NBT reduction. The SOD activity is expressed as $\mathrm{U} / \mathrm{mg}$ of protein [30].

\section{Glutathione-S-transferase (GST) activity}

The reaction between 1-chloro-2,4-dinitrobenzene (CDNB) and reduced glutathione results in formation of dinitrophenylthioether which is measured at $340 \mathrm{~nm}$ for $3 \mathrm{~min}$ at $30 \mathrm{~s}$ intervals [31]. The enzyme activity was calculated using the extinction coefficient of E340 $=0.0096$ $\mu \mathrm{M}^{-1} \mathrm{~cm}^{-1}$ and expressed as units/mg of protein. 
$1 \mathrm{U}=$ amount of enzyme producing $1 \mathrm{mmol}$ of $\mathrm{CD}$ NB-GSH conjugate/min.

\section{Glutathione peroxidase (GPx) activity}

The GPx activity was determined as described by Pagia and Valentine [32]. The oxidized glutathione (GSSG) is reduced by glutathione reductase and NADPH. The oxidation of NADPH to NADP ${ }^{+}$is measured by a decrease in absorbance at $340 \mathrm{~nm}$. GPx activity is expressed as $\mathrm{U} / \mathrm{mg}$ of protein.

\section{Catalase (CAT) activity}

The reaction mixture contained the sample and $30 \mathrm{mM} \mathrm{H}_{2} \mathrm{O}_{2}$ in a $50 \mathrm{mM}$ phosphate buffer, $\mathrm{pH}$ 7.0. The activity was estimated by the decrease in $a b$ sorbance of $\mathrm{H}_{2} \mathrm{O}_{2}$ at $240 \mathrm{~nm}$ [33].

\section{Western blot analysis}

After the appropriate treatment schedule, cells were treated with lysis buffer $(50 \mathrm{mM}$ Tris- $\mathrm{HCl}$ (pH 7.4), $1 \mathrm{mM} \mathrm{NaF}, 150 \mathrm{mM} \mathrm{NaCl} 1 \mathrm{mM}$ EGTA, $1 \mathrm{mM}$ phenylmethanesulfonyl fluoride; $1 \% \mathrm{NP}-40$ and $10 \mathrm{mg} / \mathrm{ml}$ leupeptin). The tubes were incubated on ice for $30 \mathrm{~min}$, which was followed by centrifugation at $12,000 \mathrm{rpm}$ for $30 \mathrm{~min}$ at $4^{\circ} \mathrm{C}$. The supernatant containing proteins were aliquoted and analyzed for protein content [24]. The samples containing $50 \mu \mathrm{g}$ of proteins were separated on 8-12\% SDS-polyacrylamide gels and transferred onto polyvinylidene fluoride (PVDF) membranes using glycine transfer buffer (192 mM glycine, $25 \mathrm{mM}$ Tris- $\mathrm{HCl}(\mathrm{pH}$ 8.8), $20 \% \mathrm{MeOH}(\mathrm{v} / \mathrm{v}))$. Following membrane transfer, it was treated with $5 \%$ nonfat dried milk for $1 \mathrm{~h}$ at RT for blocking nonspecific sites. After membrane wash, the membrane was probed with specific primary mouse monoclonal anti-COX-2 Ab (1 : 1000, BD Biosciences Pharmingen, San Jose, CA, USA) and anti-Nrf-2 ( $1: 1000$, Calbiochem, La Jolla, CA, USA) at $4^{\circ} \mathrm{C}$ overnight. The membrane was washed and incubated for $30 \mathrm{~min}$ with secondary peroxidase-conjugated anti-rabbit IgG (1:5000). The bands were visualized with an enhanced chemiluminescence (ECL) system. Densitometry analyses of the Western blot bands were performed using ImageJ software.

\section{ELISA}

Prostaglandin E2 (PGE2) levels in the medium were measured using an enzyme linked immunosorbent assay (ab133021, Abcam, USA). A mouse IgG antibody was pre-coated onto 96-well plates. Prostaglandin E2 standards from the manufacturer kit or test samples were added to the wells, along with an alkaline phosphatase (AP) conjugated-prostaglandin E2 antibody. After incubation the excess reagents were washed away and pNpp substrate was added and was catalyzed by AP to produce a yellow color. The intensity of the yellow coloration is inversely proportional to the amount of PGE2 captured on the plate. The PGE2 levels were expressed as $\mathrm{ng} / \mathrm{mg}$ of protein.

\section{Statistical analysis}

The statistical analysis was determined using the Statistical Program of Social Sciences (SPSS), version 10.0 (IBM, Armonk, New York, USA) [34]. The data were analyzed using one-way analysis of variance (ANOVA) followed by Tukey's multiple comparison test.

\section{Results}

Protective effect of sulforaphane against acrolein-induced toxicity

Acrolein-induced toxicity was determined by MTT assay. The results show that acrolein caused dose-dependent cell death in PBMC. The $I_{20}$ value was found to be $30 \mu \mathrm{M}(p<0.01)$ (Figure $1 \mathrm{~A})$. Cytoprotection offered by sulforaphane against acrolein-induced toxicity was tested by pre-treating with different concentrations $(1 \mu \mathrm{M}, 5 \mu \mathrm{M}$ and $10 \mu \mathrm{M})$. Cell viability was observed to be $87 \%, 96 \%$ and $95 \%$ during pretreatment with $1 \mu \mathrm{M}, 5 \mu \mathrm{M}$ and $10 \mu \mathrm{M}$ sulforaphane respectively. Maximum cytoprotection $(p<0.001)$ was achieved at $5 \mu \mathrm{M}$ and $10 \mu \mathrm{M}$ pre-treatment. Thus the $5 \mu \mathrm{M}$ pre-treatment was used for determining oxidative stress and inflammation caused by acrolein in PBMC (Figure $1 \mathrm{~B}$ ). Figure $1 \mathrm{C}$ shows that sulforaphane treatment significantly reduced $(p<0.001)$ the LDH levels when compared to acrolein-treated cells. There was a non-significant difference in $\mathrm{LDH}$ release in the sulforaphane group compared to control cells.

\section{Sulforaphane inhibits acrolein-induced oxidative stress}

Sulforaphane-induced ROS generation was measured by DCF-DA. The results showed that acrolein caused a significant increase $(p<0.001)$ in ROS generation, lipid peroxide levels, protein carbonyl and sulfhydryl content when compared to control cells. Pre-treatment with sulforaphane showed a significant decline in the oxidative stress markers in ROS generation protein carbonyl and sulfhydryl content $(p<0.001)$ and lipid peroxide levels $(p<0.01)$ when compared to cells treated with acrolein (Figure $2 \mathrm{~A}-\mathrm{D}$ ).

\section{Effect of sulforaphane on TAC, TOS and antioxidant status}

Acrolein caused a significant increase $(p<$ $0.001)$ in TOC levels and a decline $(p<0.001)$ in the TAC and antioxidant status when compared 
A

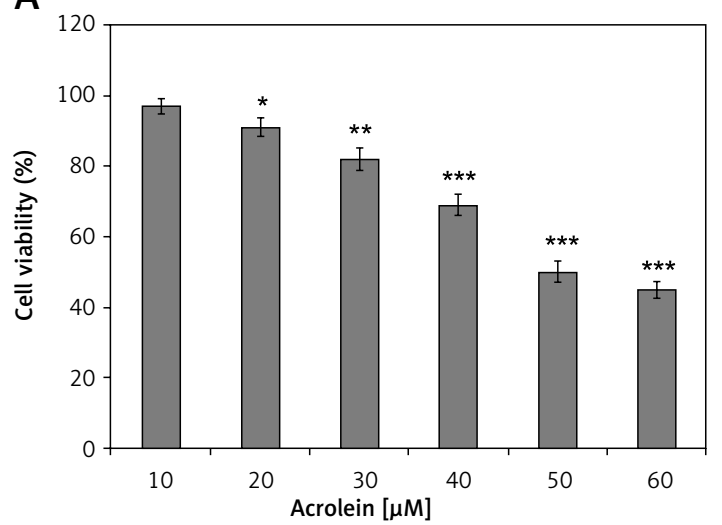

C

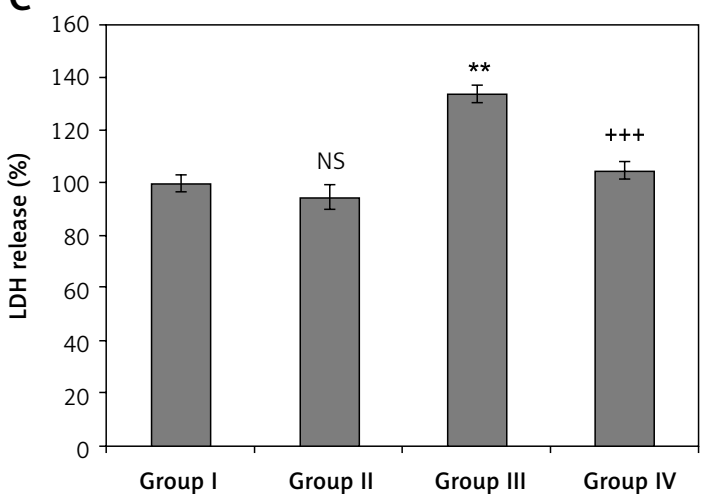

B

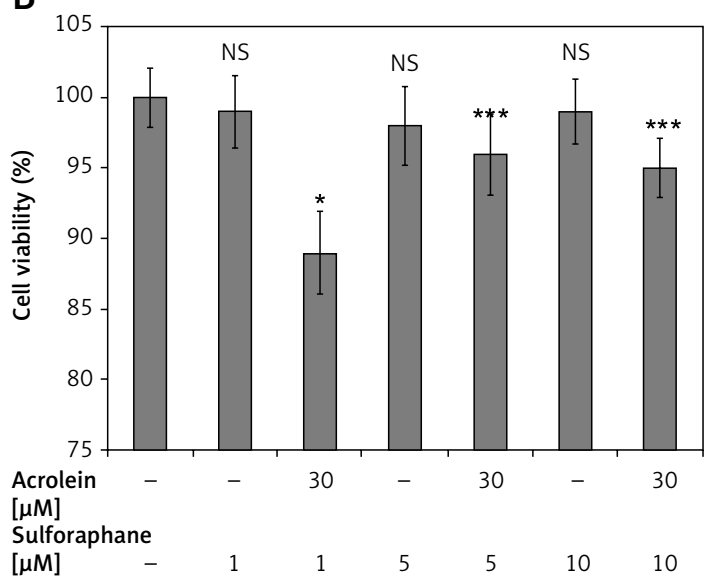

Figure 1. Sulforaphane protects against acrolein-induced toxicity in PBMC. A - Acrolein-induced cytotoxicity: MTT assay was performed to determine the cell viability. Cells were treated with acrolein (10-60 $\mu M)$ for 24 h. IC value was found to be $30 \mu \mathrm{M}$. Results are expressed as \% cell viability when compared to control cells $\left({ }^{*} p<0.05\right.$, ${ }^{* *} p<0.01,{ }^{* * *} p<0.001$; NS - non-significant when compared to control). B - Sulforaphane protects against acrolein-induced cytotoxicity: cells were treated with sulforaphane $(1 \mu \mathrm{M}, 5 \mu \mathrm{M}$ and $10 \mu \mathrm{M})$ in the presence or absence of acrolein. Cell viability was determined by MTT assay. Results are expressed as \% cell viability when compared to control cells. ${ }^{{ }^{* *}} p<0.01,{ }^{* * *} p<0.001$ in comparison to acrolein-treated cells. NS represents non-significant in comparison to control cells). C - Sulforaphane reduces LDH release: results are expressed as \% LDH leakage when compared to group I. Results shown are mean \pm SEM. ${ }^{* *} p<0.01$; NS - non-significant compared to control and ${ }^{+++} p$ $<0.001$ in comparison to group III. Groups I, II, III and IV indicate control, sulforaphane, acrolein, and sulforaphane + acrolein respectively. Results shown are mean \pm SEM (one-way ANOVA followed by Tukey’s multiple comparison tests)

to control cells. Sulforaphane showed a statistically significant increase in total antioxidant levels, GSH and non-enzymic antioxidants (SOD, CAT, GST and GPX) and a significant decrease $(p<0.001)$ in total oxidant levels when compared to acrolein-treated cells (Table I).

\section{Sulforaphane suppresses COX-2 expression and upregulates Nrf-2 levels}

The effect of sulforaphane on acrolein-mediated COX-2 and Nrf-2 levels was determined by western blot analysis. Densitometric analysis shows significant upregulation $(p<0.001)$ of COX-2 and downregulation $(p<0.001)$ of Nrf-2 during acrolein treatment when compared to control cells. The sulforaphane pre-treatment showed increased expression ( $p<0.001)$ of Nrf-2 and inhibition of COX-2 levels $(p<0.001)$ in acrolein-treated cells when compared to acrolein alone treated cells (Figure 3).

\section{Sulforaphane downregulates PGE2 levels}

Figure 4 shows a significant increase in PGE2 levels in cells treated with acrolein when compared to controls. Also, sulforaphane treatment resulted in downregulation of PGE2 compared to acrolein alone treated cells. There was a non-significant level of PGE2 in cells treated with sulforaphane alone when compared to control cells (Figure 4).

\section{Discussion}

Acrolein, a highly reactive $\alpha, \beta$-unsaturated aldehyde, is exposed to humans from industrial and environmental sources and remains in the body for several days in the active form [35]. Acrolein is metabolized in the presence of glutathione, which ultimately results in loss of endogenous antioxidant defense and thereby enhances oxidative stress. Acrolein can form adducts, and increased cellular levels have been identified in patients 
A

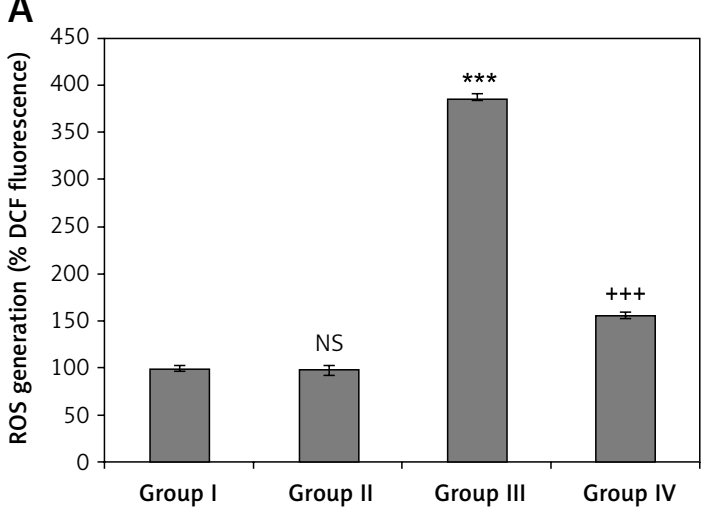

C

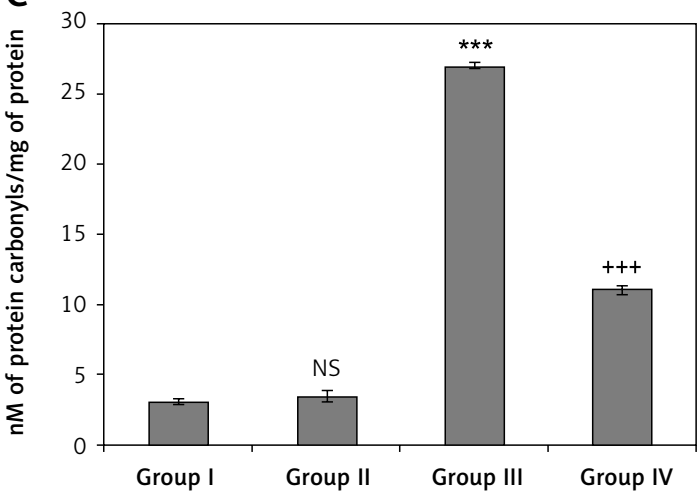

B

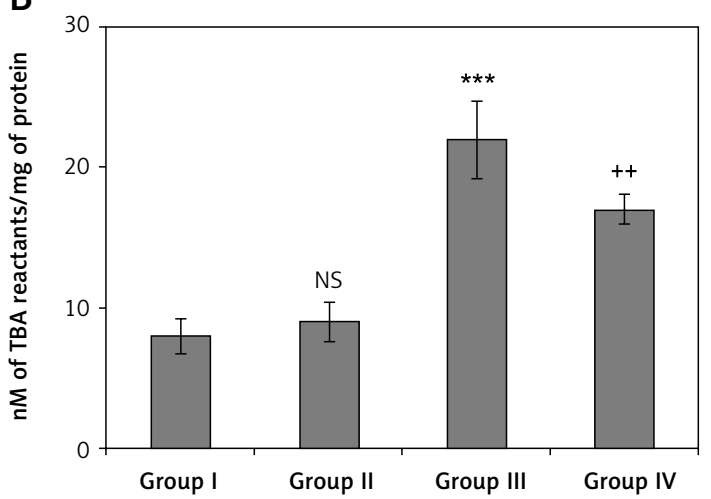

D

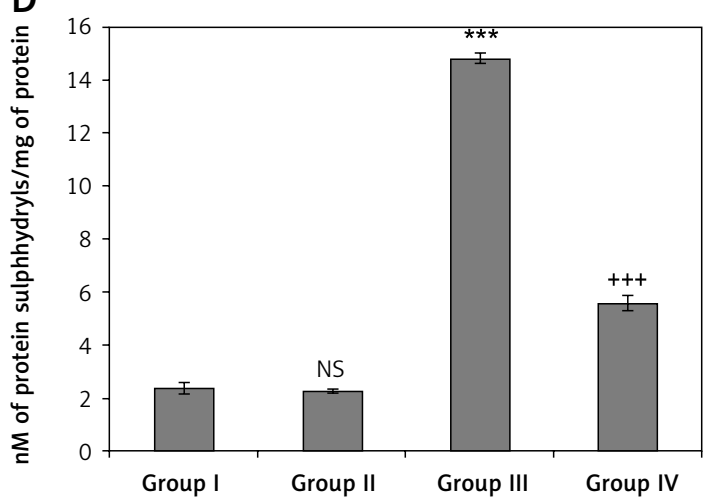

Figure 2. Sulforaphane reduces acrolein-induced oxidative stress in PBMC. A - Sulforaphane inhibits ROS generation: results are expressed as percentage of ROS generated in comparison to control. B - Sulforaphane reduces lipid peroxide levels: results are expressed as nanomoles of TBARS formed/mg of protein. C - Sulforaphane inhibits protein carbonyl content: results are expressed as nanomoles of protein carbonyls/mg of protein. D - Sulforaphane inhibits protein sulfhydryl content: results are expressed as nanomoles of protein sulfhydryl/mg of protein. Groups I, II, III and IV indicate control, sulforaphane, acrolein, and sulforaphane + acrolein respectively. Results shown are mean \pm SEM (one-way ANOVA followed by Tukey's multiple comparison tests). ${ }^{* * *} p<0.001$ when compared to group I and ${ }^{++} p<0.01,{ }^{+++} p<0.001$ in comparison to group III

Table I. Effect of sulforaphane and acrolein on antioxidant status

\begin{tabular}{|c|c|c|c|c|}
\hline Parameter & Group I & Group II & Group III & Group IV \\
\hline TAC & $4.2 \pm 0.02$ & $4.0 \pm 0.02^{\mathrm{NS}}$ & $1.9 \pm 0.01^{\text {***}}$ & $3.8 \pm 0.01^{+++}$ \\
\hline TOS & $10.18 \pm 1.10$ & $10.0 \pm 1.13^{\mathrm{NS}}$ & $24 \pm 1.90^{* * *}$ & $15 \pm 1.19^{+++}$ \\
\hline GSH & $41 \pm 1.11$ & $42 \pm 1.03^{\mathrm{NS}}$ & $15 \pm 1.11^{\star * *}$ & $34 \pm 1.09^{+++}$ \\
\hline GPX & $6.89 \pm 0.001$ & $6.82 \pm 0.002^{\mathrm{NS}}$ & $2.14 \pm 0.001^{* * *}$ & $5.15 \pm 0.001^{+++}$ \\
\hline GST & $45 \pm 1.10$ & $43 \pm 1.19^{\mathrm{NS}}$ & $12.98 \pm 1.87^{\star * *}$ & $37 \pm 1.19^{+++}$ \\
\hline SOD & $156 \pm 3.02$ & $154 \pm 2.87^{\mathrm{NS}}$ & $56 \pm 2.62^{\star * *}$ & $132 \pm 2.13^{+++}$ \\
\hline CAT & $1.71 \pm 0.001$ & $1.63 \pm 0.002^{\mathrm{NS}}$ & $0.82 \pm 0.001^{* * *}$ & $1.54 \pm 0.002^{+++}$ \\
\hline
\end{tabular}

Results are given as mean \pm SEM for 6 rats in each group. Groups I, II, III and IV indicate control, sulforaphane, acrolein, and sulforaphane + acrolein respectively. The units of TAC, TOS and GSH are expressed in $\mu \mathrm{mol} \mathrm{H}_{2} \mathrm{O}_{2}$ equiv/l, mmol of Trolox equiv/l, $\mathrm{nmol}$ of GSH/mg of protein respectively, while SOD, CAT and GST are expressed in units/mg protein. NS represents a non-significant value compared to group I, while ${ }^{* * *}$ and ${ }^{+++}$indicate $p<0.001$ in comparison to groups I and III respectively.

with various disease conditions [36-38]. A substantial increase in serum acrolein levels has been observed in smokers [39] and exposure with cyclophosphamide (anticancer drug) [40]. The highest levels were found in a patient after consuming allyl alcohol (a herbicide), which leads to death through acute cardiotoxic effects [41]. The toxic effects of acrolein are mediated through its soluble nature in both water and alcohol, by which it readily crosses the cell membrane [42].

Acrolein-induced cytotoxic effects in various cell types were found to be dose and cell dependent. The present study showed that acrolein induced oxidative stress by significantly increasing 
various stress markers such as reactive oxygen species, lipid peroxide, protein carbonyl and sulfhydryl content. Oxidative stress and subsequent damage to proteins and lipids are well established [43]. Acrolein-induced lipid peroxide and oxidative stress have been documented in primary neonatal cultures [44] and human umbilical vein endothelial cells [45]. Acrolein specifically attacks the thiol groups of amino acids forming adducts and inactivates the functions of proteins by forming carbonyl contents [46]. In addition, oxidative stress induced by acrolein in most of the conditions is mediated through GSH depletion [47, 48]. Acrolein treatment resulted in depletion of GSH and antioxidant defense mechanisms, thus exacerbating the oxidative damage in PBMC. Imbalance in redox homeostasis leads to subsequent induction of apoptosis $[49,50]$. Controlled levels of oxidant production in the cells regulate various essential signaling pathways. However, under uncontrolled conditions, reactive oxidants exceed the capacities of antioxidant defense mechanisms and initiate redox signaling. Antioxidants are well established in cytoprotection by regulating antioxidant status and inflammation [51, 52]. Expression of phase II antioxidant enzymes is regulated by nuclear factor erythroid 2-related factor 2 (Nrf-2), a redox-sensitive transcription factor $[53,54]$. Protection through Nrf-2 induction against various stress mediators and diseased conditions has been documented [55-58]. However, we could observe that sulforaphane treatment completely offered a protective effect by decreasing the oxidative stress markers through upregulating Nrf-2 levels and enhancing the antioxidant status in PBMC. Significant upregulation of Nrf-2 and downstream antioxidant enzymes by sulforaphane has been reported to function in reducing oxidative stress during renal ischemia reperfusion injury [59]. The cardioprotective effect was mediated through Nrf-2 activation and subsequent decline in oxidative stress and DNA fragmentation [60]. The sulforaphane-induced decline in reactive oxygen species and oxidative stress has also been shown to involve inhibition of CYP activity $[16,61]$.

Acrolein-mediated oxidative stress and its associated inflammatory responses are well documented [62]. Two distinct isoforms of COX (COX-1 and (OX-2) have been identified in mammalian cells. COX-1 is involved in housekeeping functions and is constitutively expressed. Under inflammatory conditions COX-2 (inducible), which catalyzes synthesis of prostaglandins, is expressed [63]. Prostaglandins are involved in normal biological functions, but their biosynthesis is found to be higher in oxidative stress conditions, ultimately leading to acute and chronic inflammation and thereby mediating disease outcome [64]. In PBMC,
A

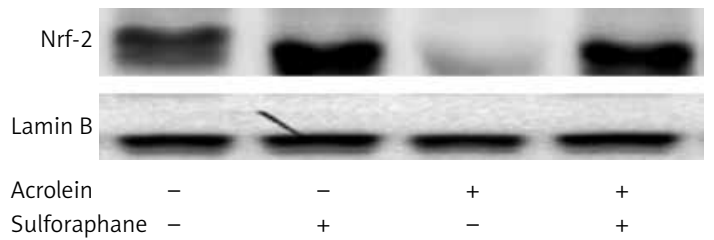

B

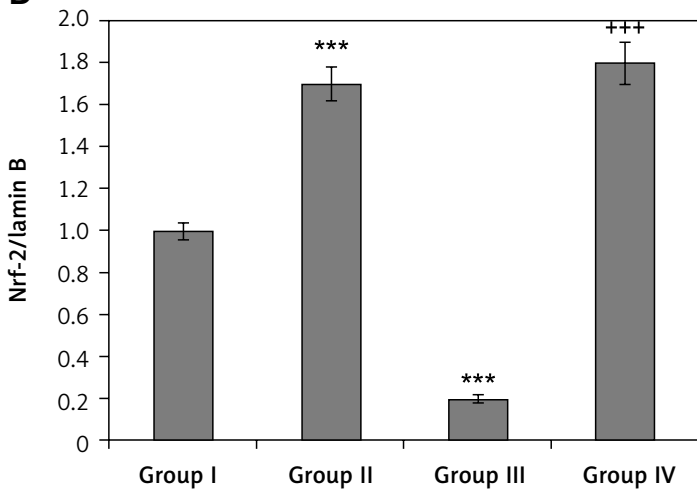

C

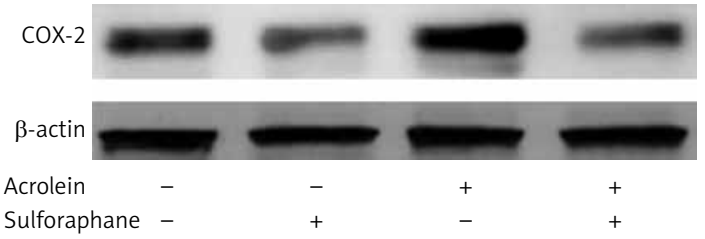

D

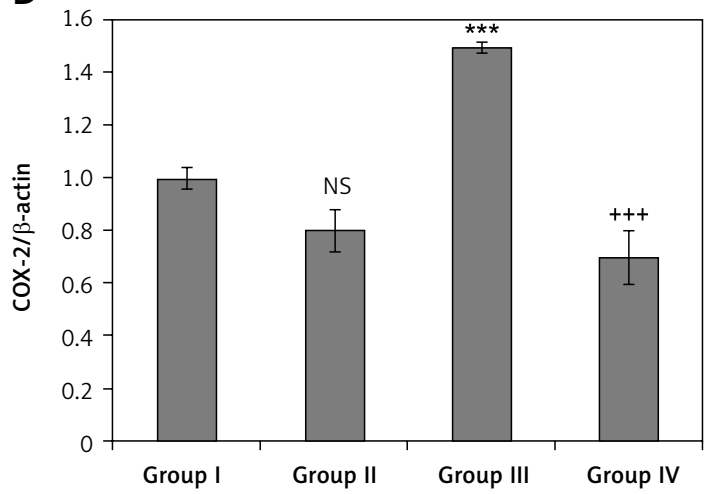

Figure 3. Sulforaphane upregulates $\mathrm{Nrf}-2$ and suppresses COX- 2 expression. A - Nrf-2 expression. C - COX-2 expression. B, D - Densitometry analysis. Statistical analyses were carried out by Student's $t$-test. Results are expressed as mean $\pm \mathrm{SEM}$. ${ }^{* * *} p$ $<0.001$, when compared to group I. ${ }^{++} p<0.001$, when compared to group III. Group I (control); group II (sulforaphane): group III (acrolein): group IV (sulforaphane + acrolein). Results are given as mean \pm SEM (one-way ANOVA followed by Tukey's multiple comparison)

acrolein showed significant upregulation of COX-2 and PGE2 levels. Acrolein-induced atherosclerosis and its associated endothelial dysfunction were mediated through COX-2 expression [5, 65]. Park et al. [66] reported that MAPK kinases mediated COX-2 and downstream expression of prostaglandins in acrolein-induced toxicity in human 


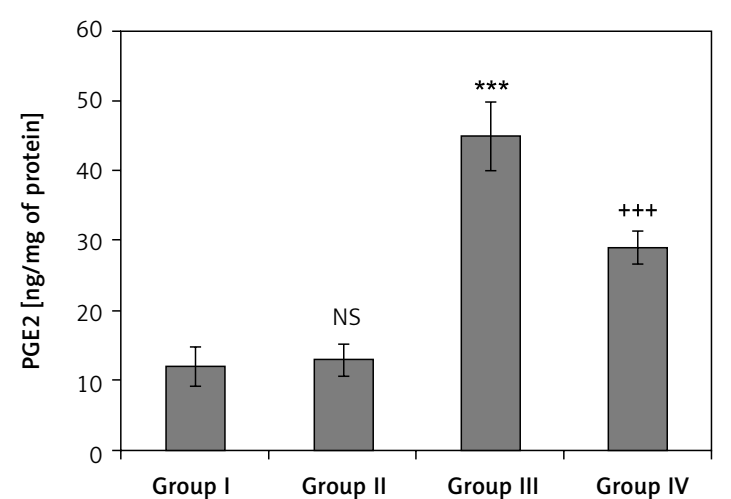

Figure 4. Sulforaphane suppresses PGE2 levels. PGE2 levels are expressed as ng/mg of protein. Results are expressed as mean \pm SEM. ${ }^{* * *} p<0.001$, when compared to group I. ${ }^{++} p<0.001$, when compared to group III. Group I (control); group II (sulforaphane): group III (acrolein): group IV (sulforaphane + acrolein). Results are given as mean \pm SEM (one-way ANOVA followed by Tukey's multiple comparison)

umbilical vein endothelial cells. A sulforaphane-induced anti-inflammatory effect has been reported by suppression of lipopolysaccharide-induced COX2 levels [67]. In addition, sulforaphane potentially inhibits PGE2 synthesis by inhibiting microsomal prostaglandin E synthase 1 and exerts therapeutic control against inflammation and cancer [68]. Sulforaphane-induced anti-inflammatory mechanisms have been reported through inhibition of NF- $\mathrm{KB}$ and inflammatory cytokines $[69,70]$. The present study shows that sulforaphane, an isothiocyanate compound, offers a protective effect against oxidative stress and inflammatory responses mediated by acrolein in PBMCs. Furthermore, therapeutic and dietary intervention using sulforaphane might be an excellent strategy to prevent oxidative stress-induced cellular damaging effects.

\section{Conflict of interest}

The authors declare no conflict of interest.

\section{References}

1. Kehrer JP, Biswal SS: The molecular effects of acrolein. Toxicol Sci 2000; 57: 6-15.

2. Esterbauer H, Schaur RJ, Zollner H. Chemistry and biochemistry of 4-hydroxynonenal, malonaldehyde and related aldehydes. Free Radical Biol Med 1991; 11: 81-128.

3. Logue JM, Price PN, Sherman MH, Singer BC. A method to estimate the chronic health impact of air pollutants in U.S. residences. Environ Health Perspect 2012; 120: 216-22.

4. Borchers MT, Wesselkamper S, Wert SE, Shapiro SD, Leikauf GD. Monocyte inflammation augments acrolein-induced Muc5ac expression in mouse lung. Am J Physiol 1999, 277: L489-97.

5. Park YS, Taniguchi N. Acrolein induces inflammatory response underlying endothelial dysfunction: a risk factor for atherosclerosis. Ann N Y Acad Sci 2008; 1126: 185-9.
6. Pugazhenthi S, Phansalkar K, Audesirk G, West A, Cabell L. Differential regulation of c-jun and CREB by acrolein and 4-hydroxynonenal. Free Radic Biol Med 2006; 40: 21-34.

7. Finkelstein El, Ruben J, Koot CW, Hristova M, van der Vliet A. Regulation of constitutive neutrophil apoptosis by the alpha, beta-unsaturated aldehydes acrolein and 4-hydroxynonenal. Am J Physiol Lung Cell Mol Physiol 2005; 289: L1019-28.

8. Tanel A, Averill-Bates DA. The aldehyde acrolein induces apoptosis via activation of the mitochondrial pathway. Biochim Biophys Acta 2005; 1743: 255-67.

9. Mohammad MK, Avila D, Zhang J, et al. Acrolein cytotoxicity in hepatocytes involves endoplasmic reticulum stress, mitochondrial dysfunction and oxidative stress. Toxicol Appl Pharmacol 2012; 265: 73-82.

10. Horton ND, Biswal SS, Corrigan LL, Bratta J, Kehrer JP. ACrolein causes inhibitor kappaBindependent decreases in nuclear factor kappaB activation in human lung adenocarcinoma (A549) cells. J Biol Chem 1999, 274: 9200-6.

11. Horton ND, Mamiya BM, Kehrer JP. Relationships between cell density, glutathione and proliferation of A549 human lung adenocarcinoma cells treated with acrolein. Toxicology 1997; 122: 111-22.

12. Matusheski NV, Jeffery EH. Comparison of the bioactivity of two glucoraphanin hydrolysis products found in broccoli, sulforaphane and sulforaphane nitrile. J Agric Food Chem 2001; 49: 5743-9.

13. Mizuno K, Kume T, Muto C, et al. Glutathione biosynthesis via activation of the nuclear factor E2-related factor 2 (Nrf2)--antioxidant-response element (ARE) pathway is essential for neuroprotective effects of sulforaphane and 6-(methylsulfinyl) hexyl isothiocyanate. J Pharmacol Sci 2011; 115: 320-8.

14. Spitz MR, Duphorne CM, Detry MA, et al. Dietary intake of isothiocyanates: evidence of a joint effect with glutathione S-transferase polymorphisms in lung cancer risk. Cancer Epidemiol Biomarkers Prev 2000; 9: 1017-20.

15. Zhao H, Lin J, Grossman HB, Hernandez LM, Dinney CP, Wu X. Dietary isothiocyanates, GSTM1, GSTT1, NAT2 polymorphisms and bladder cancer risk. Int J Cancer 2007; 120: 2208-13.

16. Skupinska K, Misiewicz-Krzeminska I, Lubelska K, Kasprzycka-Guttman T. The effect of isothiocyanates on CYP1A1 and CYP1A2 activities induced by polycyclic aromatic hydrocarbons in Mcf7 cells. Toxicol In Vitro 2009; 23: 763-71.

17. Ma Q, He X. Molecular basis of electrophilic and oxidative defense: promises and perils of Nrf2. Pharmacol Rev 2012; 64: 1055-81.

18. Calkins MJ, Johnson DA, Townsend JA, et al. The Nrf2/ ARE pathway as a potential therapeutic target in neurodegenerative disease. Antioxid Redox Signal 2009; 11: 497-508.

19. Evans PC. The influence of sulforaphane on vascular health and its relevance to nutritional approaches to prevent cardiovascular disease. EPMA J 2011; 2: 9-14.

20. Miao X, Bai Y, Sun W, et al. Sulforaphane prevention of diabetes-induced aortic damage was associated with the up-regulation of Nrf2 and its down-stream antioxidants. Nutr Metab (Lond) 2012; 9: 84.

21. Mossman T. Rapid colorimetric assay for cellular growth and survival: application to proliferation and cytotoxicity assays. J Immunol Methods 1983; 65: 55-63.

22. Royall JA, Ischiropoulos H. Evaluation of 2,7-dichlorofluorescein and dihydrorhodamine 123 as fluorescent 
probes for intracellular $\mathrm{H} 2 \mathrm{O} 2$ in cultured endothelial cells. Arch Biochem Biophy 1993; 302: 348-55.

23. Devasagayam TPA. Lipid peroxidation in rat uterus. Biochim Biophys Acta 1986; 876: 507-14.

24. Lowry OH, Rosenbrough NJ, Farr AL, Randall RJ. Pro tein measurement with the Folin phenol reagent. J Bio Chem 1951; 193: 265-75.

25. Dalle-Donne I, Rossi R, Giustarini D, Milzani A, Colombo R. Protein carbonyl groups as biomarkers of oxidative stress. Clin Chim Acta 2003, 329: 23-38.

26. Ellman GL. Tissue sulfhydryl groups. Arch Biochem Biophys 1959; 82: 70-7.

27. Erel O. A novel automated method to measure total antioxidant response against potent free radical reactions. Clin Biochem 2004; 37: 112-219.

28. Erel O. A new automated colorimetric method for measuring total oxidant status. Clin Biochem 2005; 38: 1103-1.

29. Moron MS, Depierre JW, Mannervik B. Levels of glutathione, glutathione reductase and glutathione S-transferase activities in rat lung and liver. Biochim Biophys Acta 1979, 582: 67-78.

30. Sun Y, Oberley LW, Ying L. A simple method for clinical assay of superoxide dismutase. Clin Chem 1988; 34 497-500.

31. Habig WH, Pabst MJ, Jakoby WB. Glutathione-S-transferases, the first enzymatic step in mercapturic acid formation. J Biol Chem 1974; 249: 7130-9.

32. Paglia DE, Valentine WN. Studies on the quantitative and qualitative characterisation of erythrocyte glutathione peroxidase. J Lab Clin Med 1967; 70: 158-69.

33. Aebi H. Catalase. In: Methods of enzymatic analysis. Bergmeyer HU (ed.). Academic Press, New York and London 1974; 673-7.

34. Rasband WS. Image J. U.S. National Institutes of Health, Bethesda, Maryland, USA. http://imagej.nih.gov/ij/. 1997-2014.

35. Ghilarducci DP, Tjeerdema RS. Fate and effects of acrolein. Rev Environ Contam Toxicol 1995; 144: 95-146.

36. Sakata K, Kashiwagi K, Sharmin S, et al. Increase in putrescine, amine oxidase, and acrolein in plasma of renal failure patients. Biochem Biophys Res Commun 2003; 305: 143-9.

37. Daimon M, Sugiyama K, Kameda W, et al. Increased urinary levels of pentosidine, pyrraline and acrolein adduct in type 2 diabetes. Endocr J 2003; 50: 61-7.

38. Calingasan NY, Uchida K, Gibson GE. Protein-bound acrolein: a novel marker of oxidative stress in Alzheimer's disease. J Neurochem 1999, 72: 751-6.

39. Eiserich JP, van der Vliet A, Handelman GJ, Halliwell B, Cross CE. Dietary antioxidants and cigarette smoke-induced biomolecular damage: a complex interaction. Am J Clin Nutr 1995; 62: 1490S-500S.

40. Ren S, Kalhorn TF, Slattery JT. Inhibition of human aldehyde dehydrogenase 1 by the 4-hydroxycyclophosphamide degradation product acrolein. Drug Metab Dispos 1999; 27: 133-7.

41. Toennes SW, Schmidt K, Fandino AS, Kauert GF. A fatal human intoxication with the herbicide allyl alcohol (2-propen-1-ol). J Anal Toxicol 2002; 26: 55-7.

42. Stevens JF, Maier CS. Acrolein: sources, metabolism, and biomolecular interactions relevant to human health and disease. Mol Nutr Food Res 2008; 52: 7-25.

43. Tomic S, Brkic S, Maric D, Mikic AN. Lipid and protein oxidation in female patients with chronic fatigue syndrome. Arch Med Sci 2012; 8: 886-91.

44. Lovell MA, Xie C, Markesbery WR. Acrolein, a product of lipid peroxidation, inhibits glucose and glutamate up- take in primary neuronal cultures. Free Radic Biol Med 2000; 29: 714-20.

45. Park YS, Misonou Y, Fujiwara N, et al. Induction of thioredoxin reductase as an adaptive response to acrolein in human umbilical vein endothelial cells. Biochem Biophys Res Commun 2005; 327: 1058-65.

46. Pocernich CB, Cardin AL, Racine CL, Lauderback CM, Butterfield DA. Glutathione elevation and its protective role in acrolein-induced protein damage in synaptosomal membranes: relevance to brain lipid peroxidation in neurodegenerative disease. Neurochem Int 2001; 39: 141-9.

47. Rahman I, Adcock IM. Oxidative stress and redox regulation of lung inflammation in COPD. Eur Respir J 2006; 28: 219-42

48. Ansari MA, Keller JN, Scheff SW. Protective effect of Pycnogenol in human neuroblastoma SH-SY5Y cells following acrolein-induced cytotoxicity. Free Radic Biol Med 2008; 45: 1510-9.

49. Mark RJ, Lovell MA, Markesbery WR, Uchida K, Mattson MP. A role for 4-hydroxynonenal, an aldehydic product of lipid peroxidation, in disruption of ion homeostasis and neuronal death induced by amyloid beta-peptide. J Neurochem 1997; 68: 255-64.

50. Liu-Snyder P, McNally H, Shi R, Borgens RB. Acrolein-mediated mechanisms of neuronal death. J Neurosci Res 2006; 84: 209-18.

51. Çetin A, Çiftçi O, Otlu A. Protective effect of hesperidin on oxidative and histological liver damage following carbon tetrachloride administration in Wistar rats. Arch Med Sci 2016; 12: 486-93.

52. Qiao Y, Jiang P, Gao Y. Lutein prevents osteoarthritis through Nrf2 activation and downregulation of inflammation. Arch Med Sci 2016; DOI: 10.5114/ aoms.2016.59871.

53. Kwak MK, Egner PA, Dolan PM, et al. Role of phase 2 enzyme induction in chemoprotection by dithiolethiones. Mutat Res 2001; 480-481: 305-15.

54. Ma Q. Role of nrf2 in oxidative stress and toxicity. Annu Rev Pharmacol Toxicol 2013; 53: 401-26.

55. Toyama T, Sumi D, Shinkai Y, et al. Cytoprotective role of Nrf2/Keap1 system in methylmercury toxicity. Biochem Biophys Res Commun 2007; 363: 645-50.

56. Rajo Al, Rada P, Egea J, Rosa AO, Lopez MG, Cuadrado A. Functional interference between glycogen synthase kinase- 3 beta and the transcription factor Nrf2 in protection against kainate-induced hippocampal cell death. Mol Cell Neurosci 2008; 39: 125-32.

57. Johnson JA, Johnson DA, Kraft AD, et al. The Nrf2-ARE pathway: an indicator and modulator of oxidative stress in neurodegeneration. Ann N Y Acad Sci 2008; 1147: 61-9.

58. Chen PC, Vargas MR, Pank AK, et al. Nrf2-mediated neuroprotection in the MPTP mouse model of Parkinson's disease: critical role for the astrocyte. Proc Natl Acad Sci USA 2009; 106: 2933-8.

59. Yoon HY, Kang NI, Lee HK, Jang KY, Park JW, Park BH. Sulforaphane protects kidneys against ischemia-reperfusion injury through induction of the Nrf2-dependent phase 2 enzyme. Biochem Pharmacol 2008; 75: 2214-23.

60. Angeloni C, Leoncini E, Malaguti M, Angelini S, Hrelia P, Hrelia S. Modulation of phase II enzymes by sulforaphane: implications for its cardioprotective potential. J Agric Food Chem 2009; 57: 5615-22.

61. Maheo K, Morel F, Langouet S, et al. Inhibition of cytochromes P-450 and induction of glutathione S-transferases by sulforaphane in primary human and rat hepatocytes. Cancer Res 1997; 57: 3649-52. 
62. Comer DM, Elborn JS, Ennis M. Inflammatory and cytotoxic effects of acrolein, nicotine, acetylaldehyde and cigarette smoke extract on human nasal epithelial cells. BMC Pulm Med 2014; 14: 32.

63. O'Leary KA, de Pascual-Teresa S, Needs PW, Bao YP, O'Brien NM, Williamson G. Effect of flavonoids and vitamin E on cyclooxygenase-2 (COX-2) transcription. Mutat Res 2004; 551: 245-54.

64. Rizos CV, Liberopoulos EN, Tellis CC, Tselepis AD, Elisaf MS. The effect of combining rosuvastatin with sartans of different peroxisome proliferator receptor-gamma activating capacity on plasma 8-isoprostane prostaglandin F2a levels. Arch Med Sci 2013; 9: 172-6.

65. Lee SE, Park YS. Korean Red Ginseng water extract inhibits COX-2 expression by suppressing p38 in acrolein-treated human endothelial cells. J Ginseng Res 2014; 38: 34-9.

66. Park YS, Kim J, Misonou Y, et al. Acrolein induces cyclooxygenase-2 and prostaglandin production in human umbilical vein endothelial cells: roles of p38 MAP kinase. Arterioscler Thromb Vasc Biol 2007; 27: 1319-25.

67. Woo KJ, Kwon TK. Sulforaphane suppresses lipopolysaccharide-induced cyclooxygenase-2 (COX-2) expression through the modulation of multiple targets in COX-2 gene promoter. Int Immunopharmacol 2007; 7: 1776-83.

68. Zhou J, Joplin DG, Cross JV, Templeton DJ. Sulforaphane inhibits prostaglandin E2 synthesis by suppressing microsomal prostaglandin E synthase 1. PLoS One 2012; 7: e49744.

69. Heiss E, Herhaus C, Klimo K, Bartsch H, Gerhauser C. Nuclear factor kappa $B$ is a molecular target for sulforaphane-mediated anti-inflammatory mechanisms. J Biol Chem 2001; 276: 32008-15.

70. Rose P, Won YK, Ong CN, Whiteman M. Beta-phenylethyl and 8-methylsulphinyloctyl isothiocyanates, constituents of watercress, suppress LPS induced production of nitric oxide and prostaglandin E2 in RAW 264.7 macrophages. Nitric Oxide 2005; 12: 237-43. 